\title{
Influence of Mn doping on ZnO defect-related emission
}

\author{
T.R. Stara, I.V. Markevich \\ V. Lashkaryov Institute of Semiconductor Physics, NAS of Ukraine, \\ 41, prospect Nauky, Kyiv 03028, Ukraine \\ Phone: +38(044)525-72-34; e-mail: stara_t@ukr.net
}

\begin{abstract}
Defect related emission in undoped and doped with manganese $\mathrm{ZnO}$ ceramics was investigated. Mn concentration $N_{\text {Mn }}$ was varied from $10^{19}$ to $10^{21} \mathrm{~cm}^{-3}$. The samples were sintered for 3 hours in air at $1100^{\circ} \mathrm{C}$. The color of $\mathrm{ZnO}: \mathrm{Mn}$ ceramics changed from yellow to reddish-brown with increasing the Mn content. Photoluminescence (PL) spectra of prepared samples were measured at room temperature and analyzed by Gaussian fitting. PL of undoped ceramics exhibited itself as intense broad band peaking at about $550 \mathrm{~nm}$. Two effects were shown to occur as a result of $\mathrm{Mn}$ doping: i) drastic quenching of self-activated PL accompanied by gradual red-shift of spectral boundary of the quenching with increasing the Mn content; ii) appearance of a new emission band peaking at $645 \mathrm{~nm}$ that becomes dominant in the PL spectrum at $N_{\mathrm{Mn}}=10^{20} \mathrm{~cm}^{-3}$. The observed effects were believed to be due to re-absorption of self-activated $\mathrm{ZnO}$ emission by Mn-related centers. The following recombination in excited centers was supposed to occur by both radiative and nonradiative ways, the former being responsible for $645 \mathrm{~nm}$ PL band.
\end{abstract}

Keywords: ZnO ceramics, photoluminescence.

Manuscript received 11.10.16; revised version received 25.01.17; accepted for publication 01.03.17; published online 05.04.17.

\section{Introduction}

Zinc oxide doped with manganese attracts much attention due to the influence of this dopant on $\mathrm{ZnO}$ varistor behavior and magnetic properties. Thus, the majority of research is focused on the electrical and magnetic characteristics of this material, whereas information on $\mathrm{ZnO}: \mathrm{Mn}$ light emission is rather scarce. The latter can be accounted for by the fact that $\mathrm{ZnO}: \mathrm{Mn}$, contrary to some other II-VI compounds (ZnS:Mn, ZnSe:Mn, CdS:Mn), exhibits quite weak emission. It has been shown that doping $\mathrm{ZnO}$ with $\mathrm{Mn}$ results in suppression of self-activated luminescence [1-6]. This effect, however, was not investigated in detail, and its mechanism was not decisively established. In addition, the presence of Mn-related band in ZnO:Mn emission spectrum is still a matter of debate. Some authors believe that a new emission band arises due to Mn doping [7$10]$, while the others assert that only redistribution of the intensities of initially present emission bands occurs [25]. Thus, to understand the mechanisms of the processes that result in modification of $\mathrm{ZnO}$ emission by the $\mathrm{Mn}$ doping further study is required. One can expect that the clarification of these mechanisms will give the possibility to control the emission in this material. In this work, the influence of $\mathrm{Mn}$ content on defect-related photoluminescence (PL) in $\mathrm{ZnO}: \mathrm{Mn}$ ceramics was investigated in order to clarify the origin of suppression of $\mathrm{ZnO}$ emission by Mn doping.

\section{Experimental procedure}

Undoped and doped with manganese $\mathrm{ZnO}$ ceramics were prepared. The samples were formed of the mixture of 
ZnO powder (99.99\% purity) with distilled water or $\mathrm{MnSO}_{4}$ aqueous solution. Mn content $N_{\mathrm{Mn}}$ was varied from $10^{19}$ to $10^{21} \mathrm{~cm}^{-3}$. The samples were dried at room temperature, sintered in air for 3 hours at $1100{ }^{\circ} \mathrm{C}$ and cooled with the furnace. Firm and dense ceramics with the average sizes $8 \times 3 \times 2 \mathrm{~mm}$ were obtained. The color of the doped samples changed from yellow to reddishbrown with increasing the Mn content. The ceramics were cut transversally, and PL spectra in the $400 \ldots 800 \mathrm{~nm}$ range as well as PL excitation (PLE) spectra in $250 \ldots .500 \mathrm{~nm}$ range were measured from the cleft surface at room temperature. Xe-lamp light passing through grating monochromator was used as an exciting source.

\section{Results and discussion}

The PL spectra of undoped and doped with Mn samples manifest themselves as unstructured broad bands (Fig. 1a). It is seen that drastic weakening of emission and gradual red-shift of PL band maximum occur with increasing the Mn content. PLE spectra of the observed bands exhibit the only maximum whose position coincides with that of free exciton (Fig. 1b), which is characteristic for defect-related emission in $\mathrm{ZnO}$ [11]. A slight red-shift of this maximum from 3.26 to $3.22 \mathrm{eV}$ takes place with increasing $N_{\mathrm{Mn}}$ from 0 to $10^{21} \mathrm{~cm}^{-3}$. Such an effect is usually observed in $\mathrm{ZnO}: \mathrm{Mn}$ samples at a low Mn content ( $<2$ mol.\%) and has been attributed to bandgap decrease caused by exchange interaction between $d$ electrons of $\mathrm{Mn}$ and $s$ and $p$ electrons of the host bands [7, 12].
It should be noted that quenching the visible emission as well as its red-shift as a result of Mn doping were earlier observed in $\mathrm{ZnO}$ ceramics, films and nanostructures [1-6] and were often ascribed to redistribution of green and orange PL bands intensities due to suppression of self-activated green emission [2$6]$. This suppression was accounted for by the decrease of concentrations of zinc interstitials $\mathrm{Zn}_{i}$ and/or oxygen vacancies $\mathrm{V}_{\mathrm{O}}$ as a result of $\mathrm{Mn}$ incorporation [2-5, 13]. However, it is known that, in addition to self-activated green band peaked at about $2.40 \mathrm{eV}$ (510-520 nm) [1416], another one peaked at about $2.30 \mathrm{eV}(530-540 \mathrm{~nm})$ and related to residual $\mathrm{Cu}$ impurity is usually present in PL spectrum of intentionally undoped $\mathrm{ZnO}$ [14-16]. The intensity of this Cu-related band in the samples prepared in air or oxygen ambient is usually higher than that of the self-activated one $[15,16]$. Besides, as Fig. 1a shows, quenching the visible emission by Mn doping takes place not only in green but also in orange spectral region.

It was stated that in undoped $\mathrm{ZnO}$ defect-related emission consisted of several overlapping bands, namely, of two abovementioned green ones as well as self-activated orange at $2.03 \mathrm{eV}(610 \mathrm{~nm})$ and red at $1.72 \mathrm{eV}(720 \mathrm{~nm})[14,16]$. To clarify modification of each of these bands due to Mn doping, deconvolution of PL spectra by Gaussian fitting was made for both undoped and Mn-doped samples (Fig. 2).

It is seen that in undoped samples the self-activated green band is rather weak and the Cu-related one dominates in the PL spectrum (Fig. 2a). In the samples with $N_{\mathrm{Mn}}=1 \cdot 10^{19} \mathrm{~cm}^{-3}$, the self-activated green band
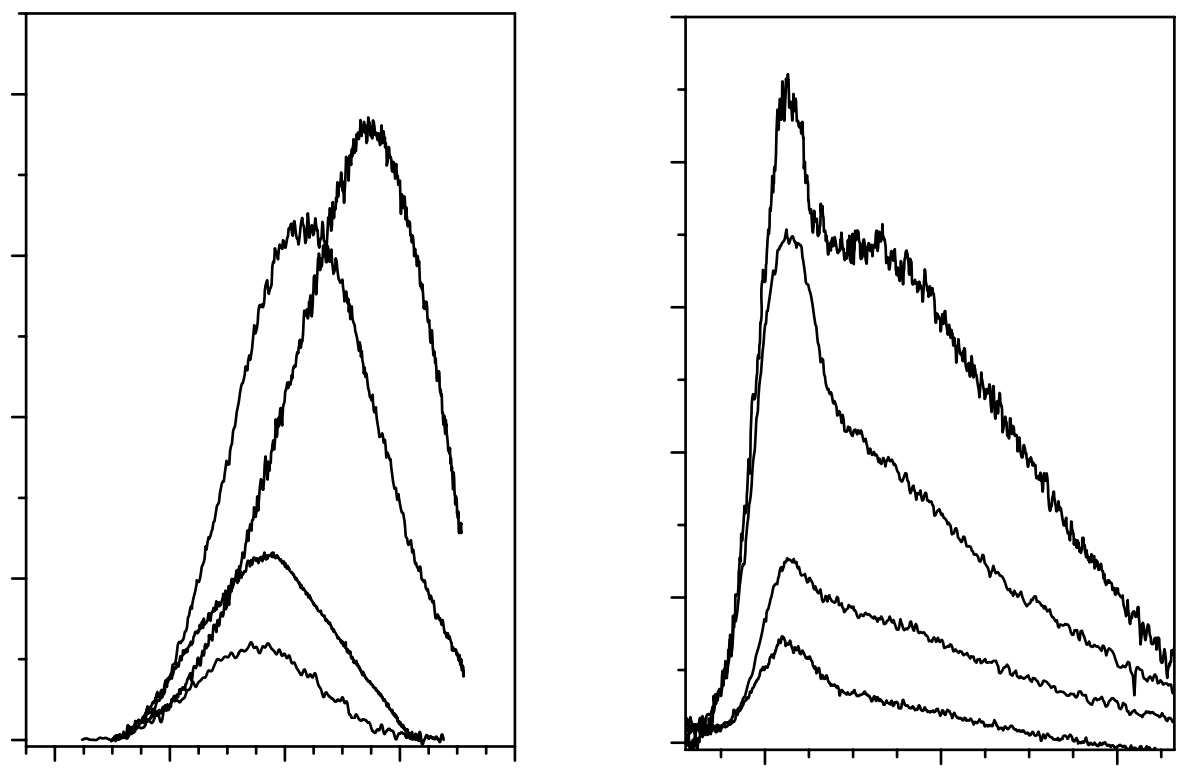

Fig. 1. PL (a) and PLE (b) spectra of ZnO:Mn ceramics with $N_{\mathrm{Mn}}=0(1) ; 1 \cdot 10^{19}(2) ; 1 \cdot 10^{20}(3)$ and $1 \cdot 10^{21} \mathrm{~cm}^{-3}(4)$. 
disappears in fact, and the intensity of Cu-related band becomes lower than that of the orange one; simultaneously, a new red-orange band peaking at $1.92 \mathrm{eV}$ (645 nm) appears (Fig. 2b). At $N_{\mathrm{Mn}}=10^{20} \mathrm{~cm}^{-3}$, disappearance the Cu-related emission and weakening the orange band with respect to the red one occur, while the PL band at $1.92 \mathrm{eV}(645 \mathrm{~nm})$ becomes dominant in PL spectrum (Fig. 2c). At $N_{\mathrm{Mn}}=1 \cdot 10^{21} \mathrm{~cm}^{-3}$, only $1.72 \mathrm{eV}(720 \mathrm{~nm})$ and $1.92 \mathrm{eV}(645 \mathrm{~nm})$ bands are observed, decreasing the intensity of the former with respect to that of the later takes place (Fig. 2d). Thus, two effects demonstrate themselves under Mn doping: i) suppression of initial PL, the effect of enhancing and extending from green to red spectral region with increasing the Mn content; ii) appearance of a new PL band at $1.92 \mathrm{eV}(645 \mathrm{~nm})$.
The reported data on $\mathrm{ZnO}: \mathrm{Mn}$ materials show that doping $\mathrm{ZnO}$ with $\mathrm{Mn}$ results in appearance of absorption in the visible spectral region, which exhibits itself as an unstructured "tail" in the absorption spectra [12, 17-22]. The intensity of this tail arises, and its spectral boundary shifts toward lower energies with increasing the Mn content [12, 17, 19, 21, 22], which produces at first yellow, then orange and at last reddish-brown color of the samples [2, 19, 22]. This effect was attributed to absorption of incident photons by $\mathrm{Mn}_{\mathrm{Zn}}{ }^{2+}$ ions caused by intra $d$-shell electron transitions from the ground to excited states $[17,19]$. The absence of any structure in the absorption tail leads to supposition that these excited states are located in some band continuum [17, 23, 24]. The origin of this absorption tail, however, requires further study. One should expect that formation of this absorption "tail" will result in re-absorption of self-
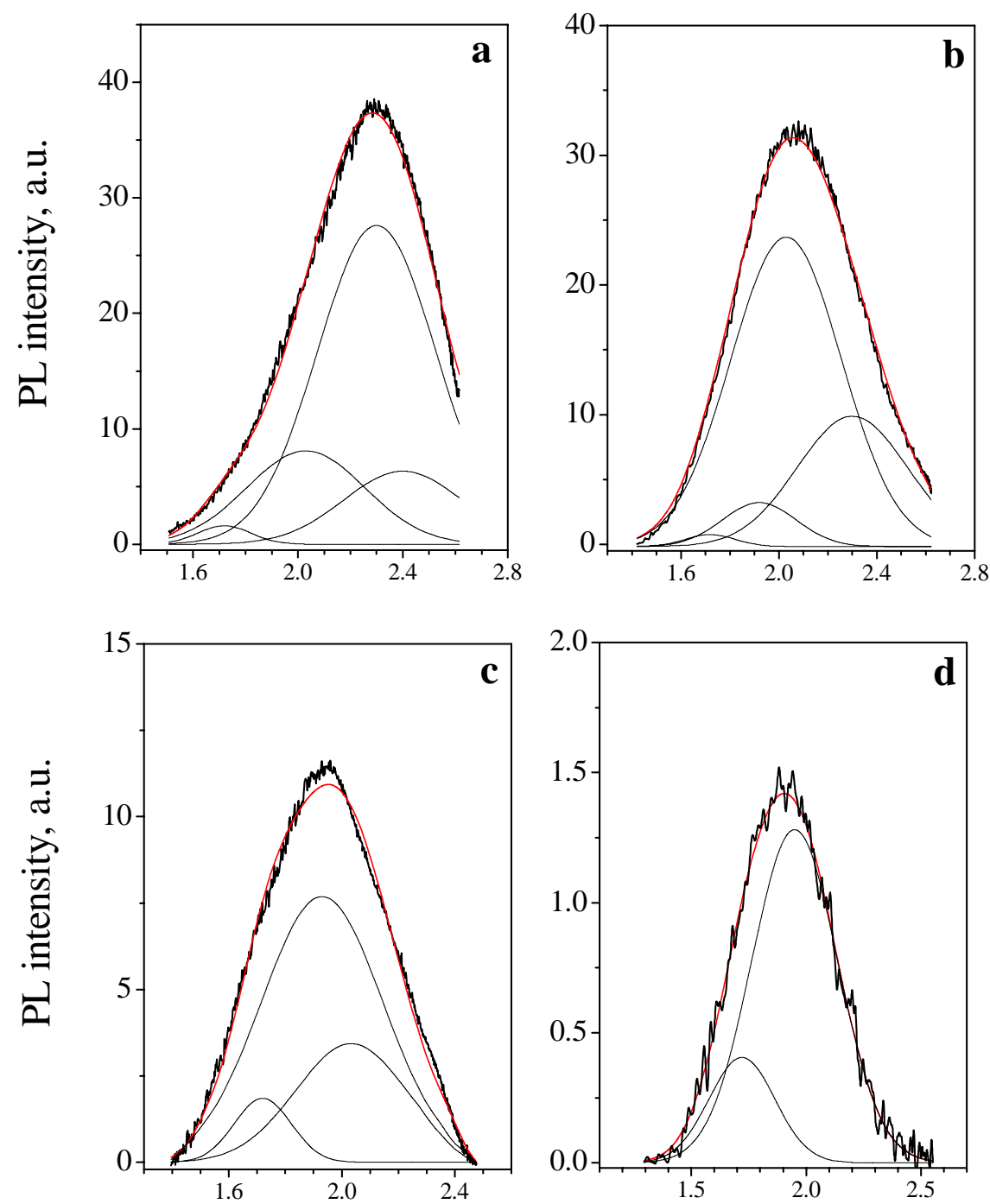

\section{Energy, eV}

Fig. 2. Gaussian deconvolution of PL spectra for undoped (a) and doped samples with $N_{\mathrm{Mn}}=1 \cdot 10^{19}$ (b), $1 \cdot 10^{20}$ (c) and $1 \cdot 10^{21} \mathrm{~cm}^{-3}(\mathrm{~d})$. 
activated PL by Mn-related centers and, so, to quenching the emission caused by native and Cu-related defects.

It is known that intense emission bands in the spectral region of 2.07...2.14 eV (580...600 nm) appear in $\mathrm{ZnS}, \mathrm{ZnSe}$, CdS and CdSe compounds due to doping with $\mathrm{Mn}$, which is ascribed to intra-shell ${ }^{4} \mathrm{~T}_{1}-{ }^{6} \mathrm{~A}_{1}$ transitions in $\mathrm{Mn}^{2+}$ ions incorporated to the host lattice [24]. At the same time, the presence of Mn-related emission in $\mathrm{ZnO}: \mathrm{Mn}$ is thus far a subject of debate. Some authors affirm that this emission is completely absent and only nonradiative recombination in excited Mn-related centers occurs [2, 3, 24]. At the same time, PL bands at $2.12 \mathrm{eV}(586 \mathrm{~nm})$ [25], $2.07 \mathrm{eV}(600 \mathrm{~nm})$ [7], $1.95 \mathrm{eV}(636 \mathrm{~nm})$ [8] and $1.91 \mathrm{eV}(650 \mathrm{~nm})$ [9] were found in doped with manganese $\mathrm{ZnO}$ thin films [8, 25], ceramics [9] and nanopowders [7], which was ascribed to the radiative intra-shell transitions in $\mathrm{Mn}$ ions. Intense emission bands at $2.0 \mathrm{eV}(620 \mathrm{~nm})$ and $1.69 \mathrm{eV}$ $(730 \mathrm{~nm})$ were also observed in electroluminescence spectra of ZnO:Mn ceramics [26]. Narrow green PL bands at $2.36 \mathrm{eV}(526 \mathrm{~nm})$ and $2.34 \mathrm{eV}$ (530 nm) with specific PLE spectra were revealed in $\mathrm{ZnO}: \mathrm{Mn}$ nanopowders [8] and ceramics [1], accordingly. The band at $2.34 \mathrm{eV}$ appeared only after additional annealing at $900{ }^{\circ} \mathrm{C}$ of sintered at $1200{ }^{\circ} \mathrm{C}$ ceramics, which was ascribed to changes in the intrinsic defect concentration [1]. The aforementioned PL band at $1.92 \mathrm{eV}(645 \mathrm{~nm})$ in our $\mathrm{ZnO}: \mathrm{Mn}$ ceramics should be also believed to be caused by Mn-related centers. In fact, this emission appears under doping $\mathrm{ZnO}$ with $\mathrm{Mn}$ and enhances with increasing the Mn content side by side with suppression of the other PL bands. The weakness of Mn-related emission in $\mathrm{ZnO}: \mathrm{Mn}$ can be accounted for by supposition that recombination in excited $\mathrm{Mn}$ ions can occur by both radiative and nonradiative ways, the later being dominant.

The reported data on $\mathrm{ZnO}: \mathrm{Mn}$ emission show that the intensity and spectral position of Mn-related PL band in different samples depend essentially on the preparation technique. This effect was accounted for by different sites of Mn ions in the host lattice [8] as well as their interaction with $\mathrm{Zn}_{i}[2,5,13]$ and $\mathrm{V}_{\mathrm{O}}$ [1-5]. The possibility of Mn cluster formation also should be taken into account $[6,27]$. To elucidate the influence of native defects on Mn-related emission in $\mathrm{ZnO}: \mathrm{Mn}$ ceramics further investigations are planned.

\section{Conclusion}

To elucidate the effect of $\mathrm{Mn}$ doping on $\mathrm{ZnO}$ defectrelated emission, PL spectra of $\mathrm{ZnO}$ ceramics undoped and doped with manganese were measured and analyzed using Gaussian fitting. As a result of $\mathrm{Mn}$ doping, quenching all the self-activated PL bands was observed, gradual red-shift of spectral boundary of this quenching from the green to red spectral region taking place with increasing the $\mathrm{Mn}$ content from $10^{19}$ to $10^{21} \mathrm{~cm}^{-3}$. Simultaneously, it was found appearance of a new PL band peaking at $1.92 \mathrm{eV}(645 \mathrm{~nm})$ that became dominant in PL spectra at $N_{\mathrm{Mn}}=10^{20} \mathrm{~cm}^{-3}$. As ZnO doping with $\mathrm{Mn}$ is known to cause formation of the absorption "tail" in the visible spectral range, the quenching effect can be accounted for by the re-absorption of self-activated PL by Mn-related centers. This explanation is in accordance with the change of sample color from yellow to reddishbrown with increasing the $\mathrm{Mn}$ content, which is accompanied by the red shift of PL quenching boundary. Recombination in the excited Mn-related centers has been supposed to occur by both radiative and nonradiative ways. The former was believed to be responsible for $1.92 \mathrm{eV}(645 \mathrm{~nm}) \mathrm{PL}$ band. The weakness of this emission leads to the conclusion that the nonradiative process is dominant.

\section{Acknowledgment}

This research has been financially supported by National Academy of Sciences of Ukraine (project III-4-16).

\section{References}

1. J.A. Garcia, A. Remon, J. Piqueras, Influence of Bi and $\mathrm{Mn}$ on the green luminescence of $\mathrm{ZnO}$ ceramics // J. Appl. Phys. 62, p. 3058-3059 (1987).

2. M. Liu, A.H. Kitai, P. Mascher, Point defects and luminescence centers in zinc oxide and zinc oxide doped with manganese // J. Lumin. 54, p. 35-42 (1992).

3. X.T. Zhang, Y.C. Liu, J.Y. Zhang, Y.M. Lu, D.Z. Shen, X.W. Fan, X.G. Kong, Structure and photoluminescence of Mn-passivated nanocrystalline $\mathrm{ZnO}$ thin films // J. Crystal Growth, 254, p. 80-85 (2003).

4. U. Llyas, R.S. Rawat, Y. Wang, T.L. Tan, P. Lee, R. Chen, H.D. Sun, F. Li, S. Zhang, Alteration of Mn exchange coupling by oxygen interstitials in ZnO:Mn thin films // Appl. Surf. Sci. 258, p. 63736378 (2012).

5. M. Sima, L. Mihut, E. Vasile, M. Sima, C. Logofatu, Optical properties of $\mathrm{Mn}$ doped $\mathrm{ZnO}$ films and wires synthesized by thermal oxidation of ZnMn alloy // Thin Solid Films, 590, p. 141-147 (2015).

6. Th. Ruf, S. Repp, J. Urban, R. Thomann, E. Erdem, Competing effects between extrinsic and intrinsic defects in pure and Mn-doped ZnO nanocrystals // J. Nanopart. Res. 18, p. 109 (1-11) (2016).

7. M. Nakayama, H. Tanaka, K. Masuko, T. Fukushima, A. Ashida, N. Fujimura, Photoluminescence properties peculiar to the Mnrelated transition in a lightly alloyed $\mathrm{ZnMnO}$ thin film grown by pulsed laser deposition // Appl. Phys. Lett. 88, p. 241908-(1-3) (2006).

8. A.J. Reddy, M.A. Kokila, Y. Nagabhushana, J.L. Rao, B.M. Nagabhushana, C. Shivakumara, R.P.S. Chakradhar, EPR and photoluminescence studies of $\mathrm{ZnO}: \mathrm{Mn}$ nanophosphors prepared by solution combustion rout // Spectrochimica Acta A, 79, p. 476-480 (2011). 
9. Th.-L. Phan, Structural, optical and magnetic properties of polycrystalline $\mathrm{Zn}_{1-\mathrm{x}} \mathrm{Mn}_{\mathrm{x}} \mathrm{O}$ ceramics // Solid State Communs. 151, p. 24-28 (2011).

10. M. Xin, Li. Zh. Hu, D.-P. Liu, N.-S. Yu, Effect of Mn doping on the optical, structural and photoluminescence properties of nanostructured thin film synthesized by sol-gel technique // Superlattices and Microstructures, 74, p. 234-241 (2014).

11. I.V. Markevich, V.I. Kushnirenko, L.V. Borkovska, B.M. Bulakh, Role of excitons in the excitation of deep-level emission in $\mathrm{ZnO}$ crystals // phys. status solidi (c), 7, p. 1605-1608 (2010).

12. S. Senthilkumaar, K. Rajendran, S. Banerjee, T.K. Chini, V. Sengodan, Influence of Mn doping on the microstructure and optical property of $\mathrm{ZnO} / /$ Mater. Sci. Semicond. Proc. 11, p. 6-12 (2008).

13. J. Han, P.Q. Mantas, A.M.R. Senos, Defect chemistry and electrical characteristics of undoped and Mn-doped ZnO // J. Europ. Ceram. Soc. 22, p. 49-59 (2002).

14. U. Ozgur, Ya.I. Alivov, C. Liu, A. Teke, M.A. Reshchikov, S. Dogan, V. Avrutin, S.-J. Cho, H. Morkos, A comprehensive review of $\mathrm{ZnO}$ materials and devices // Appl. Phys. Rev. 98, p. 041301 (1-102) (2005).

15. I. Markevich, T. Stara, O. Kolomys, A.S. Romanyuk, V. Strelchuk, Influence of annealing in $\mathrm{Zn}$ vapor on the luminescence of MgZnO ceramics // phys. status solidi (c), 11, p. 1485-1487 (2014).

16. I.V. Markevich, T.R. Stara, V.I. Bondarenko, About self-activated orange emission in $\mathrm{ZnO} / /$ Semiconductor Physics, Quantum Electronics and Optoelectronics, 18, p. 134-137 (2015).

17. T. Fukumura, Zh. Jin, A. Ohtomo, H. Koinuma, M. Kawasaki, An oxide-diluted magnetic semiconductor: Mn-doped ZnO // Appl. Phys. Lett. 75, p. 3366-3368 (1999).

18. V.R. Shinde, T.P. Gujar, C.D. Lokhande, R.S. Mane, S.-H. Han, Mn-doped and undoped $\mathrm{ZnO}$ films: A comparative structural, optical and electrical properties study // Mater. Chem. Phys. 96, p. 326-330 (2006).
19. E. Chikoidze, Y. Dumont, F. Jomard, O. Gorochov, Electrical and optical properties of ZnO:Mn thin films grown by MOCVD // Thin Solid Films, 515, p. 8519-8523 (2007).

20. H.-Fu Zhang, R.-Jin Liu, H.-Fa Liu, Ch.-Xin Lei, D.-Tai Feng, Ch.-K. Yuan, Mn-doped ZnO transparent conducting films deposited by DC magnetron sputtering // Mater. Lett. 64, p. 605-607 (2010).

21. Q. Ma, X. Lv, Y. Wang, J. Chen, Optical and photocatalytic properties of Mn doped flower-like ZnO hierarchical structures // Opt. Mater. 60, p. 8693 (2016).

22. N. Radjamanickam, S. Rajashabala, K. Ramachandran, Effect of Mn-doping on the structural, morphological and optical properties of $\mathrm{ZnO}$ nanorods // Superlattices and Microstructures, 65, p. 240-247 (2014).

23. M. Godlewski, A. Wojcik-Glodowska, E. Guziewicz, S. Yatsunenko, A. Zakrzewski, Y. Dumont, E. Chikoidze, M.R. Phillips, Optical properties of manganese doped wide band gap ZnS and ZnO // Opt. Mater. 31, p. 1768 (2009).

24. R. Beaulac P.I. Archer, D.R. Gamelin, Luminescence in colloidal $\mathrm{Mn}^{2+}$-doped semiconductor nanocrystals // J. Sol. St. Chem. 181, p. 1582-1589 (2008).

25. M. Xin, L.Zh. Hu, D.P. Liu, N.-S. Yu, Effect of Mn doping on the optical, structural and photoluminescence properties of nanostructured $\mathrm{ZnO}$ thin films synthesized by sol-gel technique // Superlattices and Microstructures, 74, p. 234-241 (2014).

26. J.C. Ronfard-Haret, Influence of the sintering temperature on the electrical and luminescent properties of Mn-doped ZnO // Solid State Ionics, 167, p. 355-366 (2004).

27. Zh.-Wu Jin, Y.Z. Yoo, T. Sekiguchi, T. Chikyow, H. Ofuchi, H. Fujioka, M. Oshima, H. Koinuma, Blue and ultraviolet cathodoluminescence from Mn-doped epitaxial ZnO thin films // Appl. Phys. Lett. 83, p. 39-41 (2003). 